\title{
Ongoing initiatives within the Scottish National Health Service to affect the prescribing of SSRIs and their influence
}

\author{
${ }^{*}$ Brian Godman ${ }^{1,2,3}$, Amanj Kurdi ${ }^{1,4}$, Holly McCabe 5 , Chris F Johnson ${ }^{6}$, Corrado \\ Barbui $^{7}$, Sean MacBride-Stewart ${ }^{6}$, Simon Hurding ${ }^{8}$, Axel Leporowski ${ }^{5}$, Marion \\ Bennie $^{1}$, Alec Morton ${ }^{5}$
}

\begin{abstract}
1Strathclyde Institute of Pharmacy and Biomedicial Sciences, University of Strathclyde, Glasgow, United Kingdom. Email: Brian.Godman@strath.ac.uk; amanj.baker@strath.ac.uk; marion.bennie@strath.ac.uk 2Division of Clinical Pharmacology, Karolinska, Karolinska Institutet, Stockholm, Sweden. Email: Brian.Godman@ki.se ${ }^{3}$ Department of Public Health Pharmacy and Management, School of Pharmacy, Sefako Makgatho Health Sciences University, Garankuwa, South Africa ${ }^{4}$ Department of pharmacology, College of Pharmacy, Hawler Medical University, Erbil, Iraq ${ }^{5}$ Department of Management Science, Strathclyde Business School, University of Strathclyde, Glasgow, United Kingdom. Email: axel.leporowski@strath.ac.uk; alec.morton@strath.ac.uk; holly.mccabe.2013@uni.strath.ac.uk ${ }^{6}$ Prescribing Prescribing Support Unit, National Health Service Greater Glasgow and Clyde (NHS GGC), Glasgow, UK. Email: Sean.MacBride-Stewart@ggc.scot.nhs.uk; c.johnson2@nhs.net ${ }^{7}$ WHO Collaborating Centre for Research and Training in Mental Health and Service Evaluation, Department of Neuroscience, Biomedicine and Movement Sciences, Section of Psychiatry, University of Verona, Italy. Email: corrado.barbui@univr.it 8Primary Care Unit, NHS Scotland, Edinburgh, UK. Email: Simon.Hurding@gov.scot
\end{abstract}

\begin{abstract}
*Author for correspondence: Brian Godman, Strathclyde Institute of Pharmacy and Biomedical Sciences, University of Strathclyde, Glasgow G4 ORE, United Kingdom. Email: brian.godman@strath.ac.uk. Telephone: 0141548 3825. Fax: 01415522562 and Division of Clinical Pharmacology, Karolinska Institute, Karolinska University Hospital Huddinge, SE-141 86, Stockholm, Sweden. Email: Brian.Godman@ki.se. Telephone + 468 58581068. Fax + 46859581070
\end{abstract}

Keywords: SSRIs, Scottish NHS, expenditure, reforms, drug utilisation, generics

\begin{abstract}
Aim: Increasing use of SSRIs in Scotland, coupled with safety concerns with some SSRIs, and the increasing availability of generic SSRIs, have resulted in multiple initiatives to improve the quality and efficiency of prescribing. Our aim is to assess their influence to provide future direction. Materials \& methods: PCA database to document utilisation and expenditure on SSRIs between 2001 to 2017 and document initiatives. Results: Multiple interventions over the years increased INN prescribing up to $99.9 \%$ lowering overall costs. This coupled with initiatives to limit escitalopram prescribing due to concerns with its value resulted in a 73.7\% reduction in SSRI expenditure between 2001 and 2017 despite a 2.34-fold increase in utilisation. Safety warnings resulted in a significant reduction in the prescribing of paroxetine, citalopram and escitalopram alongside a significant increase in sertraline Conclusion: Multiple initiatives have increased the quality and efficiency of SSRI prescribing in Scotland providing direction to others.
\end{abstract}

\section{Introduction}

Across countries, there has been considerable growth in the use of medicines. In part, this has been driven by aging populations, an increase in primary prevention strategies, as well as single disease model guidelines and policies [1,2]. We have also seen the continual launch of new high-priced medicines $[2,3]$. These factors combined are adding to resource pressures within countries resulting in models and initiatives to address this [2-5]. Scotland is no exception, and during the last 20 years or more there have been multiple initiatives to enhance the quality and efficiency of prescribing to help improve patient outcomes within finite resources providing direction to other countries.

A peer-reviewed, accepted author manuscript of the following in press article: Ongoing initiatives within the Scottish National Health

Service to affect the prescribing of SSRIs and their influence. / Godman, Brian; Kurdi, Amanj; McCabe, Holly; Johnson, Chris ; Barbui, Corrado; MacBride-Stewart, Sean; Hurding, Simon; Leporowski, Axel; Bennie, Marion; Morton, Alexander David. In: Journal of Comparative Effectiveness Research, 11.02.2019 
Initiatives include encouraging high rates of international non-proprietary name (INN) prescribing with generics typically seen as similar to the originator in all but a minority of situations [6-8]. This is important as there are still concerns with generics across a number of countries [9-11]. Savings once generics become available in Scotland are enhanced by their reduced costs, which can be as low as $3 \%$ of pre-patent loss originator prices [12,13]. INN prescribing is important in Scotland as pharmacists are not currently allowed to switch an originator or branded product to a generic if the physician prescribes the originator or branded product $[7,14,15]$. Alongside this, there have also been initiatives to increase the prescribing of multiple sourced products (generics) versus on-patent products in a class or related class where this does not compromise care to further save on costs. Classes include the proton pump inhibitors (PPIs), renin-angiotensin receptor blockers and statins $[12,13,15]$.

Concomitant with this, there have also been multiple measures in Scotland to improve the quality of prescribing. These include encouraging physicians to prescribe higher doses of statins to improve long term outcomes as well as initiatives to reduce the prescribing of lipid lowering agents where there have been concerns with their effectiveness $[12,15]$. There have also been national and regional initiatives in Scotland to reduce the doses of PPIs prescribed, as well as encourage regular monitoring of patients on long-term PPIs, due to concerns with the consequences of their long term use [16-19].

Depression and other mental health conditions such as anxiety disorders are prevalent in Scotland with $11.3 \%$ of the adult population in 2010 to 2011 prescribed antidepressants [20]. These high rates of prescribing are possibly influenced by Westernised societies' expectations of happiness, and consequential medicalisation of unhappiness [21,22], as well as expansion of the indications for antidepressants. The selective serotonin re-uptake inhibitors (SSRIs) are the most frequently prescribed antidepressants in Scotland, accounting for over $50 \%$ of all antidepressants prescribed in recent years $[20,23,24]$. However, unlike the PPIs, renin-angiotensin blockers and statins, the situation with antidepressants is more challenging as they are not readily interchangeable, which limits the potential for therapeutic switching within a class $[12,13,15,25,26]$. This is because antidepressants such as the SSRIs exhibit subtle differences, which can affect both their efficacy and side-effects [27-29]. Having said this, there have been activities among the Health Boards (Regions) in Scotland to limit the prescribing of escitalopram versus other SSRIs, including fluoxetine and citalopram, where there have been considerable differences in costs but limited differences in patient outcomes [ 17, 30-32]. Health Board activities included prescribing targets for escitalopram [33]. They also include switching suitable patients prescribed escitalopram prior to citalopram to now being prescribed citalopram (C Johnson personal communication). Encouragingly, $90 \%$ of patients remained on citalopram after the switch at a three-month review. Such activities are important from a health policy perspective as they help to conserve resources without compromising care.

We have also seen initiatives in other countries to influence the prescribing of antidepressants where there have been concerns. This includes instigating prescribing restrictions for duloxetine in the management of patients with depression in Sweden due to concerns with its effectiveness and costs versus other antidepressants [34], as well as education and other activities to limit the prescribing of vortioxetine again due to concerns with its cost-effectiveness $[35,36]$. Such activities are likely to continue.

We are also aware that there have be concerns with the increased risk of suicides with paroxetine as well as other SSRIs since the early 2000s [37-42]. In addition, paroxetine is associated with a higher incidence of discontinuation symptoms versus other SSRIs, which necessitates a longer period of dose reduction [43]. There have also been concerns with potential QTc interval prolongation and Torsade de Pointes with citalopram and escitalopram from 2011 onwards [44], although the latter may be infrequently reported [45]. The concerns with possible QTc interval prolongation with citalopram and escitalopram resulted in the MHRA in the UK and Health Boards in Scotland providing guidance on their use [46-69]. This included recommending alternative SSRIs for new patients, as well as for patients where there were concerns with citalopram and escitalopram. This included sertraline with evidence of potential improved effectiveness and safety versus other SSRIs [48,50,51]. We are also aware that Health Boards in Scotland have also assessed factors associated with higher doses of SSRIs being prescribed [20,52]. Available evidence does not support the routine prescribing of higher 
doses of SSRIs for the treatment of depression as this is known to increase anxiety, agitation and insomnia [53].

As a result of multiple activities in Scotland, rates of INN prescribing for the SSRIs were as high as $98 \%$ - 99\% of their total utilisation in 2007 [13]. This coupled with initiatives to limit the prescribing of escitalopram versus citalopram resulted in expenditure on the SSRIs falling in Scotland by 59\% between 2001 and 2007 despite a 2.37 fold increase in their utilisation [13]. This compares with appreciably increased expenditure for the SSRIs in Ireland (72\% higher) and Portugal (93\% higher) in 2008 and 2007 versus 2001 respectively where there were limited measures in both these countries to encourage the prescribing of lower costs multiple sourced SSRIs (generics) versus originators as well as on-patent escitalopram [13,54]. Such activities are important among high income countries with universal healthcare systems due to the continuous growth in the prescribing of medicines for patients with non-communicable diseases with ageing populations resulting in constant financial pressures, which is enhanced by the continual launch of new premium priced medicines to address areas of unmet need $[2,4,55,56]$. Obtaining low prices for good quality generics, and promoting their use, is also very important in low and middle income countries where access to medicines can be an issue with high patient co-payment levels [57,58]. Without such considerations, illness among family members can be potentially catastrophic for them [58,59]. Currently, fluoxetine is included in the WHO list of essential medicines [60].

Consequently, the objectives of this paper are multiple. Firstly, to assess the influence of the various multiple measures in Scotland on the overall volume and expenditure on the SSRIs in recent years, building on the earlier analysis [13]. Secondly, assess the extent of INN prescribing as well as the extent of price reductions for SSRIs following generic availability to help fund increased prescribing volumes without increasing costs, again building on the earlier analysis [13]. Thirdly, assess the extent of changes in the utilisation of citalopram, escitalopram, paroxetine and sertraline in recent years as a result of multiple initiatives and safety warnings. The findings will help guide future activities in Scotland as well as other countries, as all countries are looking to improve the quality and efficiency of their prescribing due to continuing pressures on resources.

We are also aware that there is a growing requirement for research evidence to guide future activities and initiatives to improve the selection, affordability, and rationality of prescribing of medicines for patients with mental disorders, which can be considered as public health psychopharmacology [61]. We hope our findings helps to start addressing this deficit.

\section{Methodology}

\subsection{Utilisation and expenditure data}

We used the prescription costs analysis (PCA) data in Scotland to analyse utilisation and expenditure data in ambulatory care [62]. PCA data is compiled by the Information Services Division (ISD) of NHS Scotland, which is an open source data set collecting data on the utilization and expenditure of medicines dispensed in community pharmacies in Scotland. The NHS in Scotland is a tax payer funded free at point of access health service, with currently no co-payment for medicines.

Information extracted from the PCA for each SSRI (N06AB - [63]) between 2001 and 2017 included: their generic name, commercial name(s), formulation(s), drug strength(s), number of dispensed units, cost per unit and total expenditure. The costs are in Great Britain pounds (GB£s) and include the gross ingredient costs (GIC) and cost per item for all SSRIs medicines dispensed during this period. No adjustment for inflation for prices was made, which is in line with previous studies, due typically to the rapid reduction in prices in the UK once originators become available as generics $[12,13,64]$.

Whilst we are aware NHS Scotland routinely uses defined daily doses (DDDs) when presenting and discussing utilization data in line with international guidance $[23,63,65]$ especially when different strengths are available such as citalopram $(10 \mathrm{mg}, 20 \mathrm{mg}, 40 \mathrm{mg})$ and sertraline $(50 \mathrm{mg}, 100 \mathrm{mg})$. However, we used items dispensed as we wanted to track this to reflect individual prescriptions, especially following changes in prescribing guidance, similar to the situation with lipid lowering agents and PPIs $[15,19]$. In the case of patients with chronic diseases such as depression, a prescription in terms of 'items dispensed' is usually for 28 or 56 days. However, as previously identified, there can be a tendency in recent years for physicians to increase the length of a prescription to help with their growing workloads [15]. 


\subsection{Demand-side measures}

As before, ongoing activities within the Health Boards and NHS Scotland to encourage INN prescribing as well as selected SSRIs have been collated using the 4E methodology: Education, Engineering, Economics and Enforcement $[12,13.15,66]$. Education refers to initiatives such as prescribing guidance and guidelines; engineering refers to organizational or managerial interventions such as prescribing targets; economics to financial incentives such as prescribing incentive schemes; and enforcement refers to regulations from health authorities $[13,15,66]$. However, the latter is rare in Scotland with no actual enforcement of regulations as seen for instance in Sweden with compulsory generic substitution and prescribing restrictions for statins in Finland and Norway following generic simvastatin [67-69].

We did not typically undertake any time-series analyses as multiple interventions inter-linked activities were undertaken at different times both nationally and regionally between 2001 and 2017. However, we did undertake such a time-series analysis comparing the changes in the items dispensed for citalopram and escitalopram before and after the warnings regarding possible QTc interval prolongation and any subsequent influence on the utilisation of recommended SSRls such as sertraline [70]. A p value $>0.05$ was seen as significant.

\section{Results}

\subsection{Generic availability of SSRIs}

Table 1 contains details of the year of patent expiry of the different SSRIs in Scotland.

Table 1 - SSRIs and their patent expiration date in Scotland from 2001 to 2017

\begin{tabular}{|l|c|c|c|}
\hline \multicolumn{1}{|c|}{ Generic name } & $\begin{array}{c}\text { Commercial name } \\
\text { (Originator) }\end{array}$ & ATC Code & $\begin{array}{c}\text { Year of patent } \\
\text { expiration }\end{array}$ \\
\hline Fluvoxamine & Faverin $\AA$ & N06AB08 & Prior to 2000 \\
\hline Fluoxetine & Prozac $\AA$ & N06AB03 & 2000 \\
\hline Paroxetine & Seroxat $\AA$ & N06AB05 & Prior to 2000 \\
\hline Citalopram & Cipromi $\AA$ & N06AB04 & 2002 \\
\hline Sertraline & Lustrall $\AA$ & N06AB06 & 2005 \\
\hline Escitalopram & Cipralext $\AA$ & N06AB10 & 2014 \\
\hline
\end{tabular}

\subsection{Influence of multiple measures}

A number of demand-side measures have been introduced nationally and regionally in Scotland in recent years to enhance INN prescribing as well as influence the prescribing of different SSRIs due either to concerns with their safety or value. These are summarised in Table 2. 
Table 2 - Summary of principal demand-side measures introduced in Scotland between 2001 and 2017 that influenced SSRI utilization patterns $[13,17,30,31,33,40,46,48,49,51,52,71-76]$

\begin{tabular}{|c|c|c|c|}
\hline Measure & Year & $\begin{array}{c}\text { National or } \\
\text { Regional }\end{array}$ & Initiative \\
\hline \multirow{13}{*}{ Education } & 2001 to 2017 & $\begin{array}{l}\text { National and } \\
\text { Regional }\end{array}$ & $\begin{array}{l}\text { - Physicians typically trained in medical school to } \\
\text { prescribe by INN name with subsequent activities in } \\
\text { GP practices coupled with IT systems to enhance } \\
\text { INN prescribing }\end{array}$ \\
\hline & 2003 & National & - $\quad$ National warning regarding paroxetine in children \\
\hline & 2003 & $\begin{array}{l}\text { Regional } \\
\text { (Lothian) }\end{array}$ & $\begin{array}{l}\text { - Lothian highlighting the extent of savings from the } \\
\text { prescribing of generic paroxetine vs originator }\end{array}$ \\
\hline & 2006 & $\begin{array}{l}\text { Regional } \\
\text { (GGC) }\end{array}$ & $\begin{array}{l}\text { - Fluoxetine and citalopram recommended SSRIs on } \\
\text { the formulary list }\end{array}$ \\
\hline & $\begin{array}{c}2008 \\
\text { onwards }\end{array}$ & $\begin{array}{l}\text { Regional } \\
\text { (GGC) }\end{array}$ & $\begin{array}{l}\text { Educating GPs to regularly review patients on long- } \\
\text { term antidepressants (doses prescribed, } \\
\text { effectiveness, treatment duration, guideline } \\
\text { improvements and costs) }\end{array}$ \\
\hline & 2009 & $\begin{array}{l}\text { Regional } \\
\text { (GGC) }\end{array}$ & $\begin{array}{l}\text { - Fluoxetine and citalopram recommended SSRIs on } \\
\text { the formulary list }\end{array}$ \\
\hline & 2010 & $\begin{array}{l}\text { Regional } \\
\text { (GGC) }\end{array}$ & $\begin{array}{l}\text { - Sertraline added to the recommended formulary list } \\
\text { of SSRIs }\end{array}$ \\
\hline & $\begin{array}{l}2009 / 10 \text { to } \\
2015\end{array}$ & $\begin{array}{l}\text { Regional } \\
\text { (GGC) }\end{array}$ & $\begin{array}{l}\text { Review of patients receiving the same } \\
\text { antidepressant for } \geq 2 \text { years conducted among } 180 \\
\text { GP practices involving }>8000 \text { patients, the majority } \\
\text { of whom receive SSRIs }\end{array}$ \\
\hline & 2011 & National & $\begin{array}{l}\text { - MHRA warning on QT interval prolongation with } \\
\text { citalopram and escitalopram }\end{array}$ \\
\hline & $\begin{array}{l}2012 \text { and } \\
2015\end{array}$ & $\begin{array}{l}\text { Regional } \\
\text { (GGC) }\end{array}$ & $\begin{array}{l}\text { - Escitalopram and citalopram at high risk of QT } \\
\text { prolongation }\end{array}$ \\
\hline & 2012 & $\begin{array}{l}\text { Regional } \\
\text { (Tayside) }\end{array}$ & $\begin{array}{l}\text { Warnings of QT interval prolongation with } \\
\text { citalopram and escitalopram }\end{array}$ \\
\hline & 2013 & $\begin{array}{l}\text { Regional } \\
\text { (Lothian) }\end{array}$ & $\begin{array}{l}\text { - Guidance on potential risks associated with the } \\
\text { prolongation of QTc interval with different } \\
\text { psychotropic medicines }\end{array}$ \\
\hline & 2017 & $\begin{array}{c}\text { NHS } \\
\text { Grampian }\end{array}$ & $\begin{array}{l}\text { - Fluoxetine and sertraline recommended SSRIs with } \\
\text { sertraline recommended in patients with } \\
\text { cardiovascular disease (caution with citalopram) }\end{array}$ \\
\hline \multirow{6}{*}{ Engineering } & & & - \\
\hline & 2002 & National & $\begin{array}{l}\text { Audit Scotland benchmarking DDDs of non- } \\
\text { fluoxetine SSRIs and the extent of INN prescribing } \\
\text { across Scotland }\end{array}$ \\
\hline & 2007 & National & $\begin{array}{l}\text { Health improvement, Efficiency, Governance, } \\
\text { Access to services and Treatment (HEAT) targets. } \\
\text { NHS Boards to reduce the annual rate of increase } \\
\text { of defined daily dose per capita of antidepressants } \\
\text { to zero by } 2009 / 10 \text {, and put in place the required } \\
\text { support framework to achieve a } 10 \% \text { reduction in } \\
\text { future years }\end{array}$ \\
\hline & $2007 / 2008$ & $\begin{array}{l}\text { Regional } \\
\text { (Lothian) }\end{array}$ & $\begin{array}{l}\text { - Total number of prescribed items of escitalopram } \leq \\
10 \% \text { of all SSRIs (also linked with financial } \\
\text { incentive schemes - Economics) }\end{array}$ \\
\hline & $\begin{array}{l}2008 / 09 \text { to } \\
2012 / 13\end{array}$ & $\begin{array}{l}\text { Regional } \\
\text { (GGC) }\end{array}$ & $\begin{array}{l}\text { Fluoxetine \& citalopram as a \% of all SSRIs, } \\
\text { duloxetine, mirtazapine, reboxetine and venlafaxine } \\
\text { items } \geq 65 \% \text { (or an absolute increase of } 5 \% \text { ) items } \\
\text { and linked with prescribing financial incentives } \\
\text { (Economics) }\end{array}$ \\
\hline & $2009 / 10$ & $\begin{array}{l}\text { Regional } \\
\text { (GGC) }\end{array}$ & $\begin{array}{l}\text { - } \\
\text { ascitalopram prescribing }<5 \% \text { of all SSRIs items } \\
\text { (Economics) } \\
\text { - Fluoxetine 60mg capsules to } 3 \times 20 \mathrm{mg} \text { capsules } \\
\text { (GB£39/ patient as opposed to GB£360/patient) }\end{array}$ \\
\hline
\end{tabular}




\begin{tabular}{|l|c|c|l|}
\hline \multirow{2}{*}{} & $2011 / 2012$ & $\begin{array}{l}\text { Regional } \\
\text { (GGC) }\end{array}$ & $\begin{array}{l}\text { and linked to prescribing financial incentives } \\
\text { (Economics) }\end{array}$ \\
\cline { 2 - 4 } & \multicolumn{3}{|c|}{$\begin{array}{l}\text { Citalopram and escitalopram QTc prolongation } \\
\text { reviews of patients }\end{array}$} \\
\cline { 2 - 4 } $\begin{array}{l}\text { Economics } \\
\text { (in addition } \\
\text { to the above) }\end{array}$ & Ongoing & $\begin{array}{l}\text { National/ } \\
\text { Regional }\end{array}$ & $\begin{array}{l}\text { Practice incentive schemes for reaching agreed } \\
\text { prescribing targets }\end{array}$ \\
\hline \begin{tabular}{l} 
Enforcement $\begin{array}{l}\text { (although no } \\
\text { actual } \\
\text { enforcement } \\
\text { in Scotland }\end{array}$ \\
\cline { 2 - 4 }
\end{tabular} & National & $\bullet \begin{array}{l}\text { Escitalopram initial rejected for use in NHS } \\
\text { Scotland in 2002; however, accepted for use in } \\
2006\end{array}$ \\
\hline
\end{tabular}

\subsection{Total utilisation and expenditure}

There was a steady increase in the number of total SSRI items dispensed between 2001 and 2017 (Figure 1).

\section{Figure 1 - SSRI utilisation (items dispensed) in Scotland 2001 to 2017}

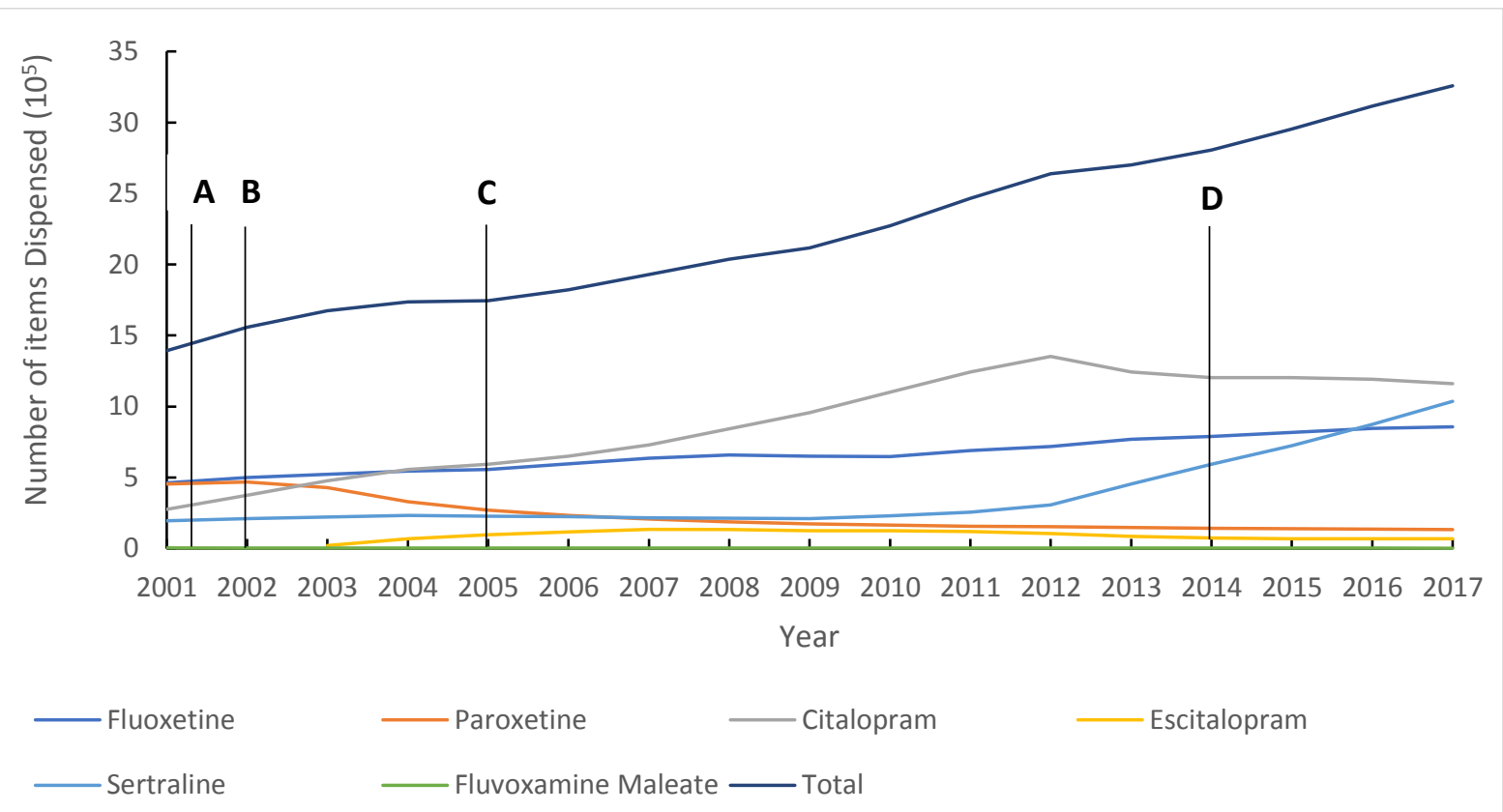

NB: The solid lines indicate the time points where generics became available; $[A]$ fluvoxamine, fluoxetine and paroxetine were already available by 2001 ; [B] generic citalopram; [C] generic sertraline; [D] generic escitalopram [D]

1.393 million items were dispensed in 2001 with a cost of GB£28.937 million, rising to 3.258 million items dispensed in 2017 at a cost of GB£7.613 million. This represents a 2.34-fold increase in SSRI utilisation during this period but a $73.7 \%$ reduction in expenditure.

The increase in SSRI utilisation during this period has been predominantly driven by increasing utilisation of citalopram, initially rising from 19.8\% of total SSRI items dispensed in 2001 (276 thousand items) to $51.3 \%$ in 2012 (1.352 million items) before falling to $35.6 \%$ in 2017 following concerns with QT prolongation (Table 2). During this period, sertraline utilisation rose appreciably from $10.32 \%$ of total SSRI utilisation in 2011 to $31.8 \%$ in 2017 . Concurrent with this, fluoxetine utilisation fell gradually from 33.2\% of total SSRI items dispensed in 2001 to $26.3 \%$ in 2017 (Figure 1). The utilisation of paroxetine fell steadily throughout the study period from $32.7 \%$ of total utilisation in 2001 to $4.1 \%$ in 2017 following safety and other concerns, although these were not exclusively attributable to paroxetine. Overall during the study period, the number of items of paroxetine dispensed fell by $70.8 \%$. There was low utilisation of escitalopram throughout the study period, 
reaching a maximum of $6.99 \%$ of total items dispensed in 2007 before falling to $2.1 \%$ of total items dispensed in 2017 (Figure 1).

Figure 2 depicts a fall in total expenditure in recent years as more SSRIs lost their patent (Table 1).

Figure 2 - Total expenditure on SSRIs in Scotland between 2001 and 2017

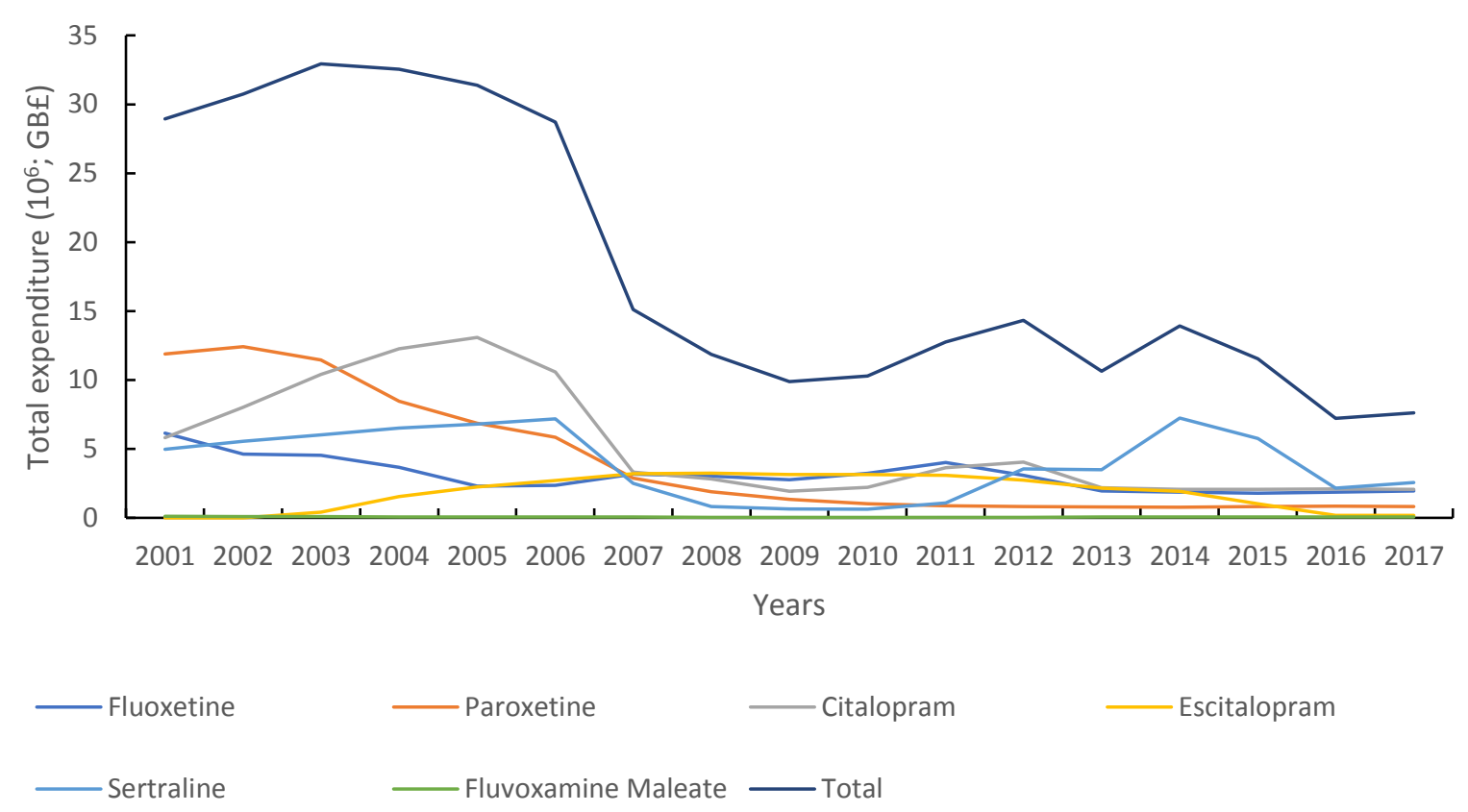

This fall in SSRI expenditure was driven by a reduction in expenditure per item of the various SSRIs especially after generic availability (Figure 3 ), with Table 3 depicting the price reductions over time for each SSRI that had lost its patent during the study period, i.e. after 2001 (Table 1). Typically, the generic versions of SSRIs were dispensed once available with high rates of INN prescribing (Table 4).

Figure 3 - Cost per item dispensed for the different SSRIs and total 2001 to 2017

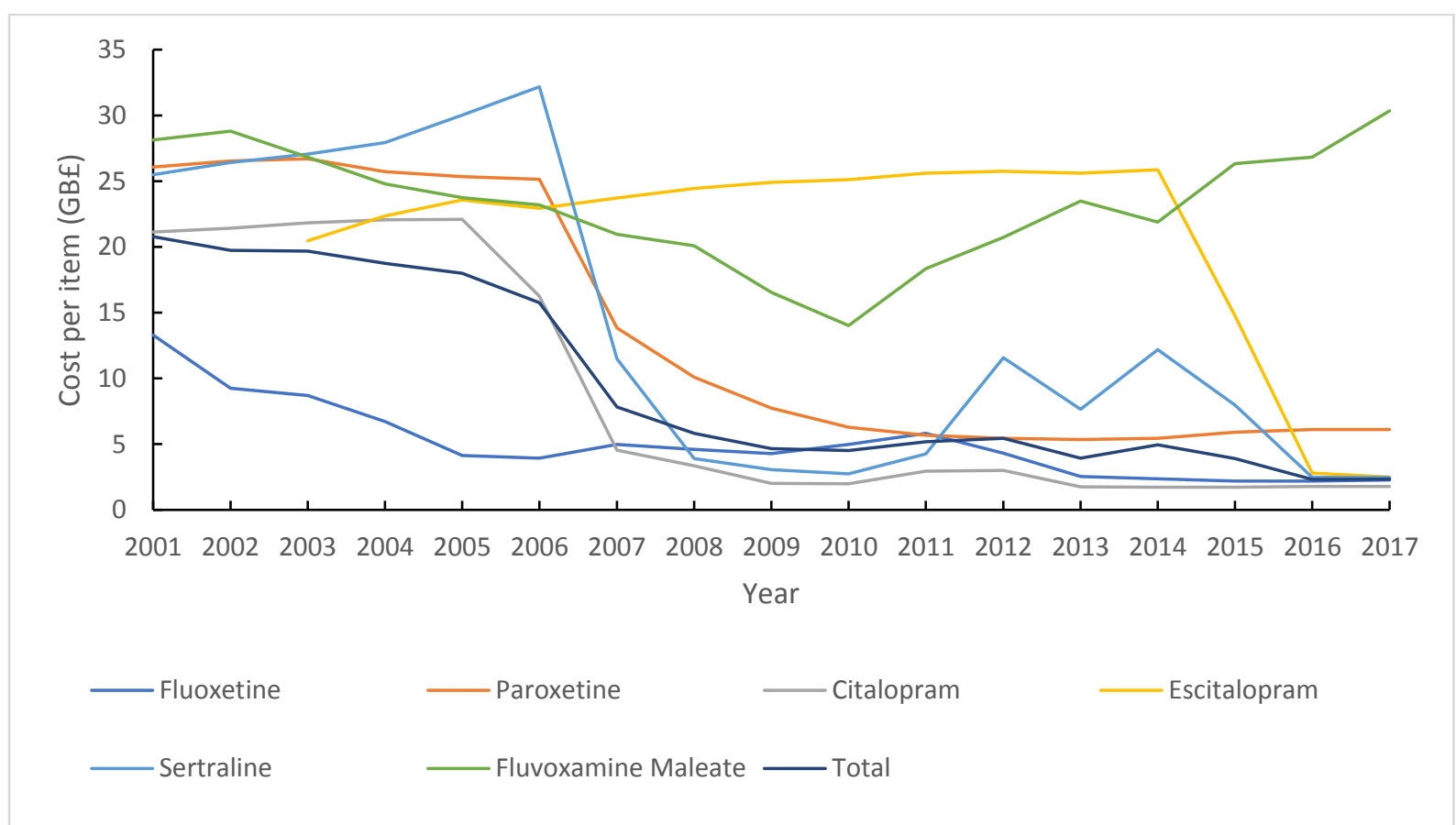


Table 3 - Price reduction in expenditure/ item dispensed for the various SSRIs in 2017 that had lost their patent after 2001 versus their prices just before patent loss

\begin{tabular}{|l|c|}
\hline SSRI & \% reduction in $\mathbf{2 0 1 7}$ \\
\hline Citalopram & 91.6 \\
\hline Sertraline & 91.8 \\
\hline Escitalopram & 90.4 \\
\hline
\end{tabular}

Table 4 - Rates of INN utilisation (items dispensed) of regularly prescribed SSRIs during the study period

\begin{tabular}{|l|c|}
\hline \multicolumn{1}{|c|}{ SSRI } & \% INN (items dispensed) \\
\hline Paroxetine & $91.4 \%-98.1 \%$ \\
\hline Fluoxetine & $98.7 \%-99.7 \%$ \\
\hline Citalopram & $99.5 \%-99.9 \%$ \\
\hline Sertraline & $98.5 \%-99.7 \%$ \\
\hline
\end{tabular}

\subsection{Differences in SSRI utilisation patterns before and after concerns with QT prolongation}

Figure 4 depicts the changes in the utilisation (items dispensed) of citalopram, escitalopram and sertraline before and after concerns with potential QT prolongation with citalopram and escitalopram (Table 2), i.e. 2001 to 2011 and after 2012

Figure 4 - Extent of utilisation of citalopram, escitalopram and sertraline in Scotland 2001 to 2017

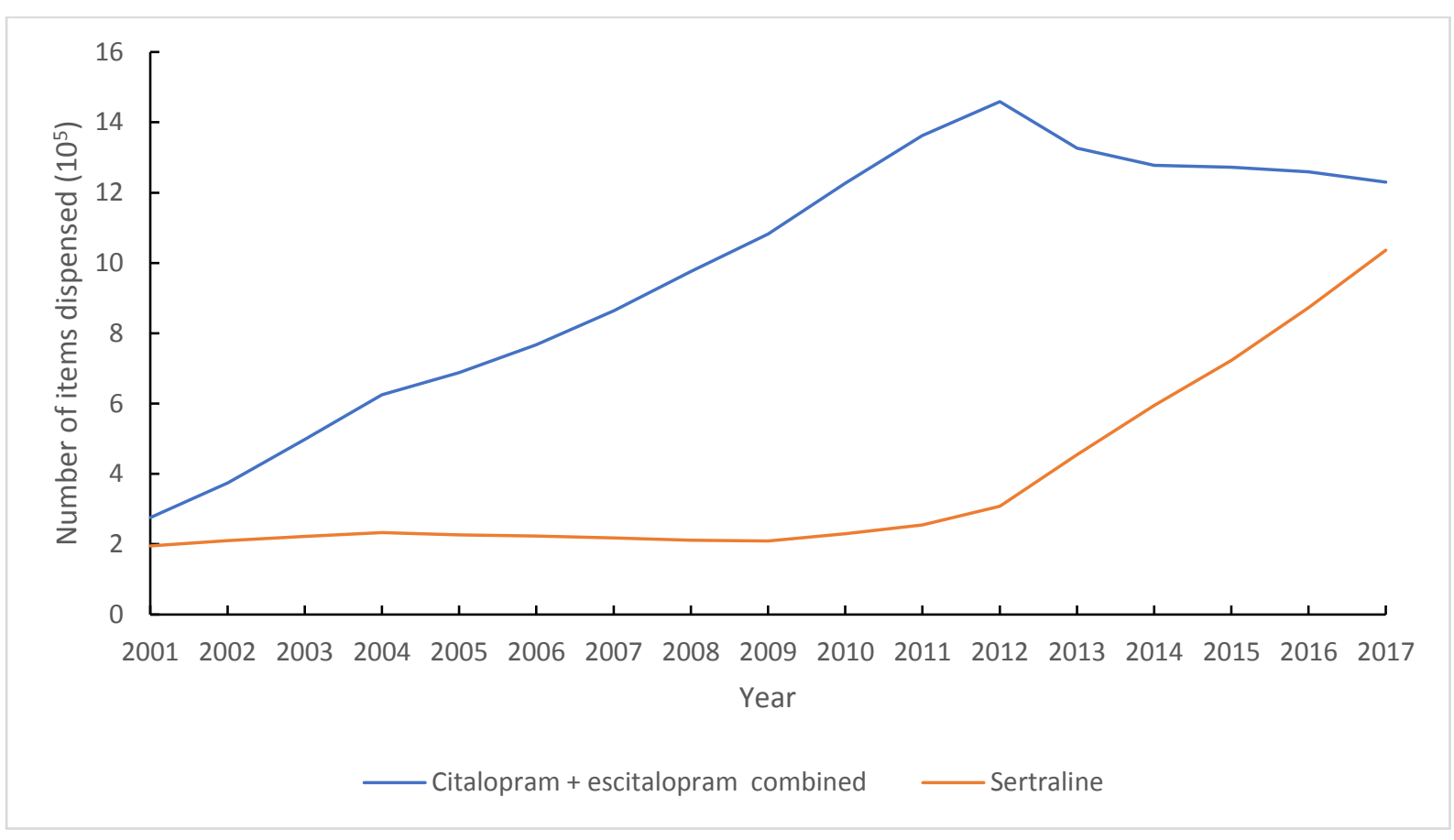

After the concerns with potential QT prolongation associated with citalopram and escitalopram use in 2012 , there was a significant decreasing trend in citalopram and escitalopram use of 142,951 items/year $(p<0.001)$ whilst the trend for prescribing of sertraline increased significantly by 141.016 items/year $(p<0.001)$.

\section{Discussion}

There has been an appreciable growth in SSRI items dispensed during the study period rising 2.34fold (Figure 1). This may well be due to a widening of the indications for SSRIs to include anxiety as well as increasing diagnosis of depression as the diagnosis of depression and its management has now always been routinely recorded and coded as part of general practice contractual obligations 
$[20,77]$, and depression has been under-detected and under-treated. This may lead to under reporting of this common illness even when patients are now more likely to seek help for their emotional distress [78]. The recent mental health and wellbeing survey suggests that one in six adults in England have a common mental disorder, with more people now seeking treatment [79]. The survey data from England indicates there has been an increase in the proportion of people with clinical anxiety or depression disorders accessing mental health treatments, up from $24 \%$ in 2007 to $39 \%$ in 2014 [79]. There is no reason why Scotland should be any different from the findings in England. Patients are also receiving longer treatment [80]. Overall, we believe this growth in SSRI prescribing in Scotland in recent years (Figure 1) has been due to a combination of factors. These include SSRIs becoming available as low cost generics (Table 1, Figure 3), and adopted as first line agents for the treatment of depression combined with additional prescribing targets (Table 2); an increase in prevalence rates and patients accessing mental health services; increasing long-term use; a lack of a regular proactive review of patients when they are stable and not in crisis; and the routine use of higher SSRI doses, which is contrary to current guidelines and evidence [17,30,43,52,77-82].

The potential associated costs with this growth in SSRI utilisation have been offset by a considerable reduction in the cost/ item for the various SSRIs apart from fluvoxamine (Figure 3). The price reductions seen for the various SSRIs over time (Table 3) mirror those for the lipid lowering agents, losartan, PPIs and risperidone $[15,19,83,84]$. This coupled with high INN (Table 4) prescribing rates has resulted in an appreciable reduction in SSRI expenditure (73.7\% reduction in 2017 versus 2001) to GB£7.613 million in 2017 (Figure 2). This is similar to the situation with lipid lowering agents and PPIs in Scotland $[15,19]$ providing guidance to other countries struggling with resource pressures.

The high rate of INN prescribing for the SSRIs in Scotland as a result of multiple activities (Table 2) is also similar to the situation seen with generic PPIs, statins, renin-angiotensin drugs and antipsychotics in Scotland $[13,15,19,84,85]$. This is encouraging and suggests no problems with the effectiveness and safety of generic SSRIs over many years. This is important for countries where there is still considerable prescribing of originator antidepressants despite the availability of good quality generics. This is not in the best interest of any key stakeholder group long term with potential resources being wasted, which could have been used to fund improved care in other situations including new medicines in patients with unmet need.

The reduction and then rise in the cost/ item for fluvoxamine (Figure 3 ) may be a reflection of its limited use (Figure 1); consequently, limited competition and need to reduce prices. This is seen in other situations across Europe [86]. However, this situation has made limited difference to the overall expenditure on SSRIs in Scotland with typically expenditure on fluvoxamine ranging from 0.21 to $0.85 \%$ of total SSRI expenditure during the study period.

The low utilisation of escitalopram in 2007 in Scotland at $6.99 \%$ of total SSRIs dispensed (7.0\% DDD basis) and $6.51 \%$ in 2008 compares favourably with $17.3 \%$ in Portugal (DDD basis) in 2007 and $30.8 \%$ in Ireland in 2008 [13] following multiple initiatives (Table 2). This is the only example of generic availability (citalopram) influencing the prescribing of patented SSRIs (escitalopram). As mentioned, GPs certainly in Glasgow were encouraged to switch suitable patients who were prescribed escitalopram prior to citalopram to citalopram. This was seen as an effective measure to conserve resources without compromising care with, as mentioned, typically $90 \%$ of patients remaining on citalopram at the three-month review. Otherwise, there was no routine switching of SSRIs between patients. This was unlike the situation with the PPIs and statins in Scotland with no perceived differences in effectiveness between them [15,19]. Unlike the PPIs and statins, there were no national indicators encouraging the prescribing of particular SSRIs, although there were regional targets discouraging the prescribing of escitalopram (Table 2) $[15,19,24]$. This recognises the fact that patients being treated for depression are considered more vulnerable and therefore their medication once seen as effective and tolerated is typically not changed. In addition, antidepressants certainly initially are prescribed as courses rather than life-long chronic treatment; consequently, a change to a different SSRI was generally through trying to influence the initial prescription rather than switching patients once prescribed a particular SSRI (Table 2). The situation with escitalopram was different (Table 2) as there was perceived limited clinical differences with citalopram; however, considerable differences in costs once generic citalopram became available (Figure 3).

The utilisation patterns for paroxetine (Figure 1) were in line with expectations following the safety warnings; however, these were not exclusive to paroxetine although paroxetine was singled out 
initially $[37,38,41]$. In addition, concerns with the need for lengthier dose reductions following the decision to stop prescribing [43].

The significant reduction in the utilisation citalopram and escitalopram, coupled with significantly increased use of sertraline in recent years, is also encouraging following safety warnings (Table 2, Figure 4). This further illustrates the favourable influence of both national and regional initiatives on effecting physician prescribing habits, which is not always the case [87-89]. As a result, again providing guidance to other countries.

\section{Limitations}

We are aware of a number of limitations with this study. This includes the fact that we were only able to analyse prescriptions dispensed and not their indication. However, two large studies in one Scottish Health Board area indicating that $87 \%$ of antidepressants were prescribed for depression, and less than $3 \%$ were prescribed for non-licensed indications [20,77]. We could also not analyse the strength of doses prescribed to ascertain whether there were any change in the doses of SSRIs prescribed although two regional Scottish studies indicate that higher SSRIs doses are possibly being prescribed more commonly $[20,78]$. We are aware that there are multiple factors which are associated with prescribing of higher SSRI doses including which anxiety disorders are being treated. For depression, which general practice a patient attends, if they are prescribed an SSRI for two years or more, and if they are co-prescribed benzodiazepines and/or z-hypnotics for more than 8 weeks [20]. We also did not analyse utilisation in terms of DDDs, which would have been more sensitive to changes in the doses of SSRIs prescribed; however, such studies have been undertaken. We could also not assess patient outcomes with the changes in SSRI prescribing patterns. Finally, from a safety perspective assessing the impact of the MHRA warning on the incidence of QTc prolongation and sudden cardiac death is very challenging as QT prolongation as a cause of death cannot be confirmed at autopsy. From a efficacy and wellness perspective, there are challenges with routinely collecting for patientlevel outcome data in ambulatory care for common mental health problems; consequently, limiting a national assessment of the impact of SSRI prescribing. Despite these limitations, we believe our findings are robust and provide guidance for the future.

\section{Conclusion}

The considerable reduction in the cost of SSRIs over the years once generics became available has resulted in lower costs despite an appreciable increase in SSRI utilisation. This is to the benefit of all key stakeholders since the savings can be used in other disease areas such as funding new medicines that address current unmet need within a resource constrained environment.

Overall, the loss of patents has not influenced SSRI prescribing patterns apart from escitalopram. This is unlike the situation seen with the PPIs and lipid lowering medicines, and reflects the differences in the effectiveness and safety of the different SSRIs.

The changes in the prescribing patterns of paroxetine, citalopram and escitalopram are encouraging and shows healthcare professionals in Scotland act quickly on safety and other warnings, providing an example to other countries.

Finally, we believe analyses such as this as part of public health psychopharmacology are justified and provide practical research findings to guide future care. Consequently, we see this discipline growing in the future.

\section{Summary points}

- There is increasing use of antidepressants including SSRIs in Scotland in recent years with expanding of indications, greater awareness and medicalisation of depression, and greater number of patients accessing treatment for their depression

- There have also been safety concerns with some SSRIs including initially paroxetine and subsequently citalopram and escitalopram

- The increasing availability of generic SSRIs. the need to conserve costs including limiting prescribing of patented escitalopram, and safety concerns has resulted in multiple initiatives in Scotland in recent years 
- High INN prescribing (up to $99.9 \%$ ) and generics up to $92 \%$ below originator prices, coupled with initiatives to limit escitalopram prescribing, resulted in a $73.7 \%$ reduction in SSRI expenditure between 2001 and 2017 despite a 2.34-fold increase in utilisation

- The safety warnings resulted in a significant reduction in the prescribing of paroxetine, citalopram and escitalopram coupled with a significant increase in the prescribing of sertraline

- Overall the multiple initiatives have increased the quality and efficiency of prescribing

\section{Funding}

The production of this paper was facilitated by a grant to Alec Morton by the University of Strathclyde under the university's New Professors' Fund.

\section{Conflicts of interest}

Chris Johnson, Marion Bennie, Simon Hurding, and Sean Macbride Stewart are all employed by NHS Scotland. The authors have no other conflicts of interest to declare.

\section{References}

‘*' - of interest, or "*** - of considerable interest

1. Garattini S, Bertele V, Godman B, Haycox A, Wettermark B, Gustafsson LL. Enhancing the rational use of new medicines across European health care systems. European journal of clinical pharmacology. 2008;64(12):1137-8.

2. Malmstrom RE, Godman BB, Diogene E et al. Dabigatran - a case history demonstrating the need for comprehensive approaches to optimize the use of new drugs. Frontiers in pharmacology. 2013;4:39.

3. Godman B, Ortwijn W, de Waure $\mathrm{C}$ et al. Links between Pharmaceutical R\&D Models and Access to Affordable Medicines. A Study for the ENVI COMMITTEE. Available at URL: http://www.europarl.europa.eu/RegData/etudes/STUD/2016/587321/IPOL STU(2016)587321 EN.pdf 4. WHO. Access to new medicines in Europe: technical review of policy initiatives and opportunities for collaboration and research. Available at URL:

http://www.euro.who.int/ data/assets/pdf file/0008/306179/Access-new-medicines-TR-PIOcollaboration-research.pdf?ua=1 [

5. Godman B, Malmstrom RE, Diogene E et al. Are new models needed to optimize the utilization of new medicines to sustain healthcare systems? Expert review of clinical pharmacology. 2015;8(1):77-94.

6. Godman B, Acurcio F, Guerra Junior AA et al. Initiatives among authorities to improve the quality and efficiency of prescribing and the implications. J Pharma Care Health Sys. 2014;1(3):1-15. 7. Duerden MG, Hughes DA. Generic and therapeutic substitutions in the UK: are they a good thing? British journal of clinical pharmacology. 2010;70(3):335-41.

8. MHRA. Antiepileptic drugs: updated advice on switching between different manufacturers' products. 2017. Available from URL: https://www.gov.uk/drug-safety-update/antiepileptic-drugsupdated-advice-on-switching-between-different-manufacturers-products\#chm-review-and-update. 9. Labiris G, Fanariotis M, Kastanioti C et al. Greek Physicians' Perceptions on Generic Drugs in the Era of Austerity. Scientifica. 2015;2015:251792.

10. Dunne SS, Shannon B, Cullen W, Dunne CP. Beliefs, perceptions and behaviours of GPs towards generic medicines. Fam Pract. 2014;31(4):467-74.

11. Fadare JO, Adeoti AO, Desalu OO et al. The prescribing of generic medicines in Nigeria: knowledge, perceptions and attitudes of physicians. Expert review of pharmacoeconomics \& outcomes research. 2016;16(5):639-50.

12. Bennie M, Godman B, Bishop I, Campbell S. Multiple initiatives continue to enhance the prescribing efficiency for the proton pump inhibitors and statins in Scotland. Expert review of pharmacoeconomics \& outcomes research. 2012;12(1):125-30.

13. Godman B, Bishop I, Finlayson AE, Campbell S, Kwon HY, Bennie M. Reforms and initiatives in Scotland in recent years to encourage the prescribing of generic drugs, their influence and implications for other countries. Expert review of pharmacoeconomics \& outcomes research. 2013;13(4):469-82

14. Ferner RE, Lenney W, Marriott JF. Controversy over generic substitution. BMJ. 2010;340:c2548. 
15. Leporowski A, Godman B, Kurdi A et al. Ongoing activities to optimize the quality and efficiency of lipid-lowering agents in the Scottish national health service: influence and implications. Expert review of pharmacoeconomics \& outcomes research. 2018;18(6):655-66.

16. NHS Scotland. The Scottish Government. National Therapeutic Indicators 2013 - Baseline

Report. Available at URL: https://www.sehd.scot.nhs.uk/publications/DC20131029nti.pdf

17. NHS Lothian. LOTHIAN PRESCRIBING BULLETIN. April/ May 2008. Available at URL:

http://www.ljf.scot.nhs.uk/PrescribingBulletins/2008/lpb/LPB\%20lssue\%20No\%2032\%20-

\%20FINAL.pdf

18. NHS Greater Glasgow and Clyde. Medicines Update Extra. ORAL PROTON PUMP

INHIBITORS. 2015. Available at URL:

http://www.ggcprescribing.org.uk/media/uploads/ps extra/mu extra 04 - 2015.pdf.

19. Godman B, Kurdi A, McCabe $\mathrm{H}$ et al. Ongoing activities to influence the prescribing of proton pump inhibitors within the Scottish National Health Service: their effect and implications. 2018. EPrint GABI Journal.

20. Johnson CF, Dougall NJ, Williams B, MacGillivray SA, Buchanan Al, Hassett RD. Patient factors associated with SSRI dose for depression treatment in general practice: a primary care cross sectional study. BMC Fam Pract. 2014;15:210.

** Good study assessing factors affecting the prescribing of SSRIs in the UK

21. Pilgrim D, Bentall R. The medicalisation of misery: a critical realist analysis of the concept of depression. J Mental Health. 1999;8(3):261-74. .

22. Dowrick C, Frances A. Medicalising unhappiness: new classification of depression risks more patients being put on drug treatment from which they will not benefit. BMJ. 2013;347:f7140.

23. NHS Scotland, ISD Scotland. Medicines for Mental Health - Years 2007/08 to 2017/18. 2018.

Available at URL: http://www.isdscotland.org/Health-Topics/Prescribing-and-

Medicines/Publications/data-tables2017.asp?id=2020\#2020.

24. Godman B, Baker A, Leporowski A et al. Initiatives to increase the prescribing of low cost generics; the case of Scotland in the international context. Medical Research Archives. 2017;5(3):134.

25. Godman B, Bucsics A, Burkhardt T et al. Potential to enhance the prescribing of generic drugs in patients with mental health problems in austria; implications for the future. Frontiers in pharmacology. 2012;3:198.

26. Martin A, Godman B, Miranda J et al. Measures to improve angiotensin receptor blocker prescribing efficiency in the UK: findings and implications. Journal of comparative effectiveness research. 2014;3(1):41-51.

27. Cipriani A, Furukawa TA, Salanti G et al. Comparative efficacy and acceptability of 21 antidepressant drugs for the acute treatment of adults with major depressive disorder: a systematic review and network meta-analysis. Lancet. 2018;391(10128):1357-66.

** Comprehensive study assessing the efficacy and acceptability of different antidepressants 28. Thorlund K, Druyts E, Wu P, Balijepalli C, Keohane D, Mills E. Comparative efficacy and safety of selective serotonin reuptake inhibitors and serotonin-norepinephrine reuptake inhibitors in older adults: a network meta-analysis. Journal of the American Geriatrics Society. 2015;63(5):1002-9 * Good study assessing the comparative effectiveness and safety of different SSRIs

29. Bauer M, Pfennig A, Severus E, Whybrow PC, Angst J, Moller HJ. World Federation of Societies of Biological Psychiatry (WFSBP) guidelines for biological treatment of unipolar depressive disorders, part 1: update 2013 on the acute and continuation treatment of unipolar depressive disorders. The world journal of biological psychiatry. 2013;14(5):334-85.

30. NHS GREATER GLASGOW AND CLYDE ANNUAL REVIEW 2010 SELF ASSESSMENT. Available at URL: http://www.nhsggc.org.uk/media/230557/nhsggc annual review 2009-

10 self assessment.pdf

31. Scottish Medicines Consortium. Escitalopram 5mg, $10 \mathrm{mg}$ and $20 \mathrm{mg}$ tablets (Cipralex) No. 253/06. 2006. Available at URL:

https://www.scottishmedicines.org.uk/files/escitalopram Cipralex 253-06 .pdf.

32. Svensson S, Mansfield PR. Escitalopram: superior to citalopram or a chiral chimera? Psychotherapy and psychosomatics. 2004;73(1):10-6.

33. NHS Lothian. LOTHIAN PRESCRIBING BULLETIN. Issue 26. April/ May 2007. Available at URL: http://www.lif.scot.nhs.uk/PrescribingBulletins/2007//pb/LPB\%20lssue\%20No\%2026.pdf.

34. Godman B, Persson M, Miranda J et al. Changes in the utilization of venlafaxine after the introduction of generics in Sweden. Applied health economics and health policy. 2013;11(4):383-93 *Interesting study assessing the impact of restricting prescribing of antidepressants in Sweden 
35. Wagner G, Schultes M-T, Titscher V, Teufer B, Klerings I, Gartlehner G. Efficacy and safety of levomilnacipran, vilazodone and vortioxetine compared with other second-generation antidepressants for major depressive disorder in adults: A systematic review and network metaanalysis. Journal of affective disorders. 2018;228:1-12.

36. Hertfordshire Partnership University, NHS Foundation Trust East and North Hertfordshire Clinical Commissioning Group, Herts Valleys Clinical Commissioning Group. Guidelines on Choice and Selection of Antidepressants for the Management of Depression. Available at URL:

http://www.hpft.nhs.uk/media/1584/guidelines-on-choice-and-selection-of-antidepressants-for-themanagement-of-depression-final-oct-2016.pdf.

37. Wooltorton E. Paroxetine (Paxil, Seroxat): increased risk of suicide in pediatric patients. CMAJ. 2003;169(5):446.

38. Aursnes I, Tvete IF, Gaasemyr J, Natvig B. Suicide attempts in clinical trials with paroxetine randomised against placebo. BMC medicine. 2005;3(1):14.

39. Breggin P. Court Filing Makes Public My Previously Suppressed Analysis of Paxil's Effects. Ethical Human Psychology and Psychiatry. 2006;8(1):77-84. Available at URL: http://breggin.com/wpcontent/uploads/2003/01/courtfiling.pbreggin.6.pdf.

40. Waechter F. Paroxetine must not be given to patients under 18. BMJ. 2003;326(7402):1282-

41. Sharma T, Guski LS, Freund N, Gotzsche PC. Suicidality and aggression during antidepressant treatment: systematic review and meta-analyses based on clinical study reports. BMJ. 2016;352:i65.

42. Stone M, Laughren T, Jones ML, Levenson M, Holland PC, Hughes A, et al. Risk of suicidality in clinical trials of antidepressants in adults: analysis of proprietary data submitted to US Food and Drug Administration. BMJ. 2009;339:b2880.

43. NICE. Depression in adults: recognition and management. Clinical guideline [CG90] Published October 2009 and last updated April 2018. Available at URL:

https://www.nice.org.uk/guidance/cg90/chapter/1-Guidance\#treatment-choice-based-on-depressionsubtypes-and-personal-characteristics

44. Tran E, Dishman B. Citalopram-induced QTc prolongation: A brief review of the data. Mental Health Clinician. 2012;2(6):139-41.

45. Tampi RR, Balderas M, Carter KV, Tampi DJ, Moca M, Knudsen A, et al. Citalopram, QTc Prolongation, and Torsades de Pointes. Psychosomatics. 2015;56(1):36-43.

46. NHS Greater Glasgow and Clyde. Medicines Update Extra. DRUG INDUCED QT

PROLONGATION. May 2015. Available at URL:

http://www.ggcprescribing.org.uk/media/uploads/ps extra/medicines update extra qt prolongation may 15 incl hydroxyzine.pdf.

47. NHS Greater Glasgow and Clude. Post Script Extra. DRUG INDUCED QT PROLONGATION. December 2012. Available at URL:

http://www.ggcprescribing.org.uk/media/uploads/ps extra/pse 21.pdf.

48. TAYSIDE PRESCRIBER. Citalopram \& escitalopram:QT interval prolongation. May 2012.

Available at URL:

https://www.nhstaysideadtc.scot.nhs.uk/Antibiotic\%20site/pdf\%20docs/Tayside\%20Prescriber\%2012 2\%20-\%20escitalopram\%20and\%20citalopram\%20May\%2012.pdf.

49. MHRA. Medicines and Healthcare products Regulatory Agency. Citalopram and escitalopram: QT interval prolongation. Dec 2011. Available at URL: https://www.gov.uk/drug-safety-

update/citalopram-and-escitalopram-qt-interval-prolongation.

50. Cipriani A, La Ferla T, Furukawa TA, Signoretti A, Nakagawa A, Churchill R, et al. Sertraline versus other antidepressive agents for depression. The Cochrane database of systematic reviews. 2010(4):Cd006117

*Good study assessing the effectiveness and safety of sertraline

51. NHS Grampian. NHS Grampian Guidance for Initiating Antidepressants. May 2017. Available at URL: http://foi.nhsgrampian.org/globalassets/foidocument/foi-public-documents1---alldocuments/AntDepS.pdf.

52. Johnson CF, Williams B, MacGillivray SA, Dougall NJ, Maxwell M. 'Doing the right thing': factors influencing GP prescribing of antidepressants and prescribed doses. BMC Fam Pract. 2017;18(1):72.

** Interesting study assessing factors influencing the prescribing of antidepressants in the UK 53. Adli M, Baethge C, Heinz A, Langlitz N, Bauer M. Is dose escalation of antidepressants a rational strategy after a medium-dose treatment has failed? A systematic review. European archives of psychiatry and clinical neuroscience. 2005;255(6):387-400. 
54. Godman B, Wettermark B, van Woerkom M et al. Multiple policies to enhance prescribing efficiency for established medicines in Europe with a particular focus on demand-side measures: findings and future implications. Frontiers in pharmacology. 2014;5:106.

55. Abbing-Karahagopian V, Huerta C, Souverein PC et al. Antidepressant prescribing in five European countries: application of common definitions to assess the prevalence, clinical observations, and methodological implications. European journal of clinical pharmacology. 2014;70(7):849-57.

56. Lewer D, O'Reilly C, Mojtabai R, Evans-Lacko S. Antidepressant use in 27 European countries: associations with sociodemographic, cultural and economic factors. The British journal of psychiatry. 2015;207(3):221-6.

* Interesting study assessing antidepressant prescribing across Europe

57. World Health Organization. Improving access to and appropriate use of medicines for mental disorders. 2017. Available at URL:

http://apps.who.int/iris/bitstream/handle/10665/254794/9789241511421-

eng.pdf;jsessionid=EA10F15C6B514516A8AD9CCED0C55F9C? sequence $=1$

58. Cameron A, Ewen M, Ross-Degnan D, Ball D, Laing R. Medicine prices, availability, and affordability in 36 developing and middle-income countries: a secondary analysis. Lancet. 2009;373(9659):240-9.

59. Cameron A, Mantel-Teeuwisse AK, Leufkens HG, Laing RO. Switching from originator brand medicines to generic equivalents in selected developing countries: how much could be saved? Value in health. 2012;15(5):664-73.

60. WHO. WHO Model List of Essential Medicines - March 2017; Amended August 2017. Available online from:

http://www.who.int/medicines/publications/essentialmedicines/20th EML2017 FINAL amendedAug2 017.pdf?ua=1.

61. Barbui C, Ostuzzi G, Godman B. Public health psychopharmacology: a new research discipline comes of age? Epidemiology and psychiatric sciences. 2018;27(1):24-8.

62. ISD Scotland. Community Dispensing. Prescription Cost Analysis. Published July 2018. Available at URL: Available at URL: http://isdscotland.org/Health-Topics/Prescribing-andMedicines/Community-Dispensing/Prescription-Cost-Analysis/.

63. WHO. WHO Collaborating Centre for Drug Statistics Methodology. ATC/ DDD Index. Available at URL: https://www.whocc.no/ [

64. Godman B, Shrank W, Andersen M et al. Comparing policies to enhance prescribing efficiency in Europe through increasing generic utilization: changes seen and global implications. Expert review of pharmacoeconomics \& outcomes research. 2010;10(6):707-22.

65. NHS Scotland. National Therapeutic Indicators. 2012 - Baseline data. Available at URL: http://www.sehd.scot.nhs.uk/pca/PCA2012(M)08report.pdf.

66. Wettermark B, Godman B, Jacobsson B, Haaijer-Ruskamp FM. Soft regulations in pharmaceutical policy making: an overview of current approaches and their consequences. Applied health economics and health policy. 2009;7(3):137-47.

67. Godman B, Wettermark B, Hoffmann M, Andersson K, Haycox A, Gustafsson LL. Multifaceted national and regional drug reforms and initiatives in ambulatory care in Sweden: global relevance. Expert review of pharmacoeconomics \& outcomes research. 2009;9(1):65-83.

68. Godman B, Sakshaug S, Berg C, Wettermark B, Haycox A. Combination of prescribing restrictions and policies to engineer low prices to reduce reimbursement costs. Expert review of pharmacoeconomics \& outcomes research. 2011;11(1):121-9.

69. Martikainen JE, Saastamoinen LK, Korhonen MJ, Enlund H, Helin-Salmivaara A. Impact of restricted reimbursement on the use of statins in Finland: a register-based study. Medical care. 2010;48(9):761-6.

70. Fulcher BD, Little MA, Jones NS. Highly comparative time-series analysis: the empirical structure of time series and their methods. Journal of the Royal Society, Interface. 2013;10(83):20130048.

71. NHS Greater Glasgow and Clyde. The Greater Glasgow and Clyde Formualary. Third Edition August 2009. Available at URL:

https://www.nhsggc.org.uk/media/226772/Document\%207\%20NHS\%20Formulary\%202009.pdf 72. Scottish Medicines Consortium. Escitalopram (Cipralex). 2003. Available at URL:

https://www.scottishmedicines.org.uk/media/1651/escitalopramresubmission_070303_.pdf

73. Audit Scotland. Supporting prescribing in general practice - a progress report. June 2003.

Available at URL: https://www2.gov.scot/Publications/2010/01/18120533/3 
74. LOTHIAN PRESCRIBING BULLETIN. April/ May 2003. Available at URL:

http://www.ljf.scot.nhs.uk/PrescribingBulletins/2003/lpb/LPB\%20lssue\%20No\%202.pdf.

75. NHS Lothian Prescribing Bulletin January 2013. Available at URL:

http://www.ljf.scot.nhs.uk/PrescribingBulletins/2013lssues/LPB/Lothian\%20Prescribing\%20Bulletin\%2 Olssue\%2059\%20Jan\%202013\%20FINAL.pdf

76. NHS Scotland. Mental Health Collaborative Programme Newsletter. December 2009.

Available at URL: https://www2.gov.scot/Publications/2009/02/13140255/0

77. Johnson CF, Macdonald HJ, Atkinson P, Buchanan Al, Downes N, Dougall N. Reviewing

long-term antidepressants can reduce drug burden: a prospective observational cohort study. The

British journal of general practice. 2012;62(604):e773-9.

** Good study discussing the rationale for reviewing patients on long term antidepressants

78. Lockhart $P$, Guthrie B. Trends in primary care antidepressant prescribing 1995-2007: a

longitudinal population database analysis. The British journal of general practice. 2011;61(590):e565-

72.

79. McManus S, Bebbington $P$, Jenkins R, Brugha T. Mental health and wellbeing in England ADULT PSYCHIATRIC MORBIDITY SURVEY 2014 EXECUTIVE SUMMARY. Available at URL:

https://files.digital.nhs.uk/pdf/s/5/adult psychiatric study executive summary web.pdf.

80. Moore M, Yuen HM, Dunn N, Mullee MA, Maskell J, Kendrick T. Explaining the rise in antidepressant prescribing: a descriptive study using the general practice research database. BMJ. 2009;339:b3999.

81. Sinclair JE, Aucott LS, Lawton K, Reid IC, Cameron IM. The monitoring of longer term prescriptions of antidepressants: observational study in a primary care setting. Fam Pract.

2014;31(4):419-26.

82. Cleare A, Pariante CM, Young AH et al. Evidence-based guidelines for treating depressive disorders with antidepressants: A revision of the 2008 British Association for Psychopharmacology guidelines. Journal of psychopharmacology. 2015;29(5):459-525.

83. Godman B, Wettermark B, Miranda J, Bennie M, Martin A, Malmstrom RE. Influence of multiple initiatives in Sweden to enhance ARB prescribing efficiency following generic losartan; findings and implications for other countries. International journal of clinical practice. 2013;67(9):853-

62.

84. Bennie M, Bishop I, Godman B et al. Are specific initiatives required to enhance prescribing of generic atypical antipsychotics in Scotland?: International implications. International journal of clinical practice. 2013;67(2):170-80.

85. Bennie M, Bishop I, Godman B, Campbell S, Miranda J, Finlayson AE, et al. Are prescribing initiatives readily transferable across classes: the case of generic losartan in Scotland? Quality in primary care. 2013;21(1):7-15.

86. Dylst $\mathrm{P}$, Simoens $\mathrm{S}$. Does the market share of generic medicines influence the price level?: a European analysis. PharmacoEconomics. 2011;29(10):875-82.

87. A Fitzgerald AL, M Cikalo, J Glanville, H Wood Review of Systematic Reviews Exploring the Implementation/Uptake of Guidelines. Yorh Health Economics Consortium. Available at URL:

https://www.nice.org.uk/guidance/ph56/evidence/evidence-review-2-431762366

88. Brusamento S, Legido-Quigley H, Panteli D et al. Assessing the effectiveness of strategies to implement clinical guidelines for the management of chronic diseases at primary care level in EU Member States: a systematic review. Health policy. 2012;107(2-3):168-83.

89. Sandora TJ, Fung M, Melvin P, Graham DA, Rangel SJ. National Variability and Appropriateness of Surgical Antibiotic Prophylaxis in US Children's Hospitals. JAMA pediatrics. 2016;170(6):570-6. 